\title{
RISK OF POST STROKE PNEUMONIA DURING HOSPITALIZATION
}

\author{
Juliana Gracia G.E.P Massie ${ }^{1,5^{*}}$, Ratna Sitorus ${ }^{2}$, I Made Kariasa ${ }^{3}$, Yunisar Gultom ${ }^{4}$, Maya \\ Khairani $^{5}$, Noor Wulandari ${ }^{6}$ \\ 1. Faculty of Nursing, Universitas Indonesia, Depok-Indonesia \\ 2. Faculty of Nursing, Universitas Indonesia, Depok-Indonesia \\ 3. Faculty of Nursing, Universitas Indonesia, Depok-Indonesia \\ 4. Department of Nursing, Dr. Cipto Mangunkusumo General Hospital, Jakarta-Indonesia \\ 5. Department of Nursing, Universitas Indonesia Hospital, Depok-Indonesia \\ 6. Department of Nursing, Universitas Indonesia Hospital, Depok-Indonesia
}

*Correspondence: Juliana GEP Massie | Universitas Indonesia Hospital | juliana.gep71@ alumni.ui.ac.id

\begin{abstract}
Introduction: Post-stroke pneumonia is the most a common complication during the first few weeks after a stroke. Thus, a score is needed for the early identification of stroke patients with an increased risk of pneumonia to assist the nursing team in preventing the onset of pneumonia in stroke patients during hospitalization. This study aimed to assess the application of the A2DS2 score to predict pneumonia in acute ischemic stroke patients.

Method: This is a diagnostic study that used a cross-sectional method conducted among adult acute ischemic stroke patients. Data analysis was performed to assess the calibration and discrimination performance of the A2DS2 score.

Results: A total of 16 respondents were followed up. The incidence of post-stroke pneumonia was observed in 6 patients $(37.5 \%)$.

Conclusion: This scoring proved clinically accurate to predict the incidence of pneumonia in acute ischemic stroke patients.
\end{abstract}

Keywords: A2DS2, Pneumonia, Non-Hemorrhagic Stroke.

Received November 29, 2021; Accepted December 30, 2021

\section{INTRODUCTION}

Due to being the most common cause of death after infectious diseases, stroke is recognised as a serious health concern in Indonesia. In fact, the prevalence of stroke in Indonesia has increased from 8.3\% in 2007 to $12.1 \%$ in 2013, with $67 \%$ of all strokes being ischemic strokes (Anindhita \& Wiratman, 2017; Kemenkes-RI, 2013). In 2014, 71.4\% of the 384 stroke patients admitted to Dr. Cipto Mangunkusumo General Hospital Jakarta were ischemic stroke patients (Anindhita \& Wiratman, 2017). The disability commonly seen in the post-stroke respiratory system is closely related to both dysphagia and ineffective cough. Moreover, it can increase the risk of aspiration pneumonia, which is known to be the leading cause of non-vascular death after stroke (Sutbeyaz et al., 2010).

Post-stroke pneumonia (PSP) is the most common complication during the first few weeks after stroke. Prior studies have found the incidence of PSP to range from $2 \%$ to $57 \%$, which indicates a median incidence rate of $10 \%$ (Kulnik et al., 2014). The incidence of PSP is the highest in intensive care patients (ranging from $4.1 \%$ to 56.6\%), while in acute stroke units, general care rooms and rehabilitation units, the incidence of PSP has been reported to range from $3.9 \%$ to $45 \%$, suggesting a median incidence rate of 7.4\% (Hannawi et al., 2013). Patients with PSP experience higher mortality, longer hospitalisation periods, poorer functional outcomes and a greater need for care (Kulnik et al., 2015). Thus, the early identification of stroke patients with a high risk of developing pneumonia can assist medically with preventing the onset of pneumonia in stroke patients during hospitalisation (L. Li et al., 2014; Y. Li et al., 2014).

\section{METHOD}

This evidence-based nursing practice study involves the diagnostic testing of the A2DS2 (age, arterial fibrillation, dysphasia, severity of stroke, sex) instrument in relation to predicting the risk of pneumonia in acute ischemic stroke patients. During the initial stage of identifying the reference articles to be adapted in clinical practice, the authors conducted a literature review of 718 articles from six databases. Next, the articles were sorted by title and abstract. The inclusion criteria included keywords in the title, journal 
articles written in English or Indonesian and articles published between 1986 and 2020. When the full text was not available, articles were excluded from the review. Furthermore, after performing duplication screening, the author used the remaining three articles as references for implementing the evidence-based nursing practice. Moreover, the authors conducted a critical appraisal of the three articles to corroborate their selection.

6 electronic databases $(n=718)$ :

Cochrane Library $(n=96)$, CINAHL $(n=127)$, EBSCO $(n=179)$, ProQuest $(n=188)$, PubMed $(n=128)$

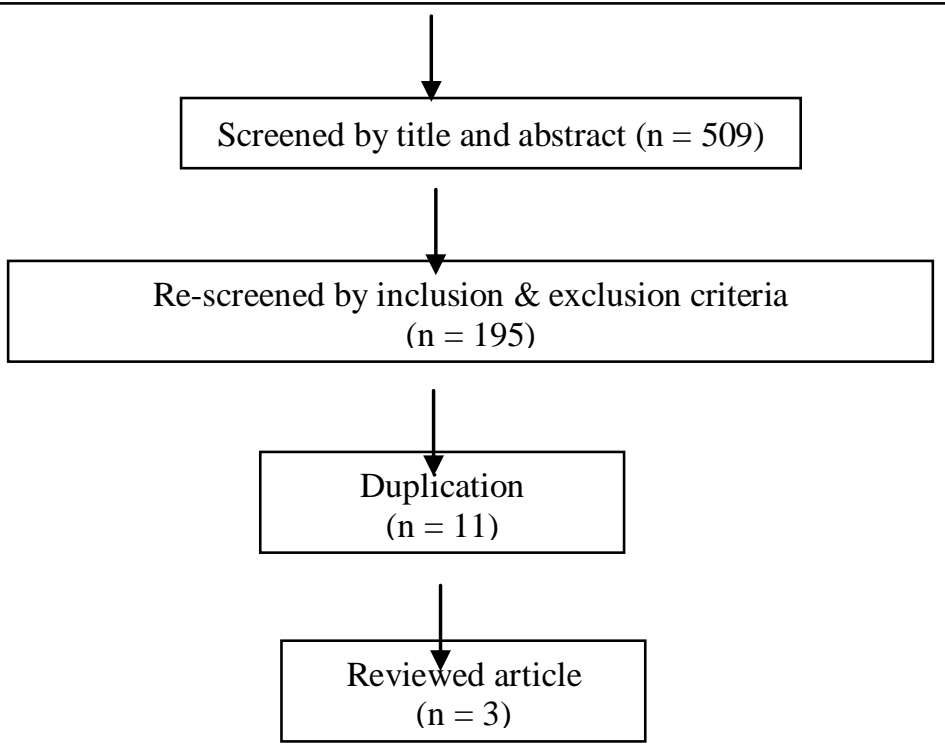

Chart 1. Search and strategy

In terms of the implementation of this evidence-based nursing practice, the subjects were all ischemic stroke patients who were undergoing treatment in the Inpatient Room, 5A Floor, Building A, Dr. Cipto Mangunkusumo General Hospital, Jakarta. The inclusion criteria were subjects aged over 18 years with a primary diagnosis of ischemic stroke and with symptom onset $<7$ days. The exclusion criterion was a diagnosis of community-associated pneumonia (CAP). The evidence-based nursing practice was implemented in the Inpatient Room, 5A Floor, Building A, Dr. Cipto Mangunkusumo General Hospital Jakarta from 28 July 2020 to 5 August 2020.

\section{RESULTS}

Table 1. Characteristic of Respondent

\begin{tabular}{lc}
\hline \multicolumn{1}{c}{ Variable } & $\mathrm{n}=16$ \\
\hline Age (Year), Mean (SD) & $55.69(14.051)$ \\
$<75$ years, n (\%) & $14(87.5)$ \\
Sex man, n (\%) & $9(56.25)$ \\
Atrial Fibrilation, n (\%) & $9(56)$ \\
Dysphagia, n (\%) & $8(50)$ \\
Post Stroke, n $(\%)$ & $4(25)$ \\
Hypertension, n $(\%)$ & $4(25)$ \\
Chronic Kidney Disease, n $(\%)$ & $2(12.5)$ \\
NIHSS Score 0 - 4, n (\%) & $2(12.5)$ \\
NIHSS Score 5 - 15, n $(\%)$ & $13(81.25)$ \\
\hline
\end{tabular}




\begin{tabular}{lc}
\hline NIHSS Score $\geq 15, \mathrm{n}(\%)$ & $1(6.25)$ \\
A2DS2 Score $<5, \mathrm{n}(\%)$ & $7(43)$ \\
A2DS2 Score $\geq 5,(\%)$ & $9(56)$ \\
\hline
\end{tabular}

Table 1. shows the characteristics of patients in the implementation of this evidence-based nursing practice. Of the 16 patients who participated in this evidence-based clinical practice, the majority were male $(56.25 \%)$, with comorbid atrial fibrillation $(56.25 \%)$, with complicated dysphagia $(50 \%)$, moderate NIHSS score $(81,25 \%)$, and A2DS2 score more than five (56\%).

Table 2. Risk of Pneumonia

\begin{tabular}{|c|c|c|}
\hline \multirow{2}{*}{ Variable } & \multicolumn{2}{|c|}{ Pneumonia } \\
\hline & Yes, n (\%) & No $(\%)$ \\
\hline \multicolumn{3}{|l|}{ Age } \\
\hline$<75$ years & $2(100)$ & $0(0)$ \\
\hline$\geq 75$ years & $4(28.5)$ & $10(71)$ \\
\hline \multicolumn{3}{|l|}{ Sex } \\
\hline Man & $4(44.4)$ & $5(55.5)$ \\
\hline Woman & $2(28.5)$ & $5(71.4)$ \\
\hline \multicolumn{3}{|l|}{ Atrial Fibrilation } \\
\hline Yes & $3(33.3)$ & $6(66.6)$ \\
\hline No & $3(42.8)$ & $4(57.1)$ \\
\hline \multicolumn{3}{|l|}{ Dysphagia } \\
\hline Yes & $4(50)$ & $4(50)$ \\
\hline No & $2(25)$ & $6(75)$ \\
\hline \multicolumn{3}{|l|}{ NIHSS Score } \\
\hline Yes & $2(28.5)$ & $5(71.4)$ \\
\hline No & $4(44.4)$ & $5(55.5)$ \\
\hline
\end{tabular}

Table 2. presents risk of pneumonia in the application of this evidence-based nursing practice. The risk of pneumonia is owned by patients with aged 75 years $(28.5 \%)$, male $(44.4 \%)$, having comorbid atrial fibrillation (33.3\%), having dysphagia (50\%), and having high NIHSS (44.4\%).

\section{DISCUSSION}

Prior studies have identified various factors associated with stroke-related pneumonia in acute ischemic stroke patients, including advanced age, sex (male), stroke severity based on the National Institute of Health Stroke Scale (NIHSS) score, dysphagia, decreased consciousness and comorbidities such as hypertension and diabetes mellitus. Based on these known risk factors, a number of scoring systems have been developed to assist clinicians in identifying and stratifying the risk of acute ischemic stroke patients developing pneumonia during hospitalisation. Among these scoring systems are the A2DS2, Kwon's score, Preventive Antibacterial Therapy in Acute Ischemic Stroke (PANTHERIS), Chumbler's score and Acute Ischemic Stroke-Associated Pneumonia (AIS-SAP) systems (Gong et al., 2016; Ji et al., 2013).

According to Anindhita and Wiratman (2017), among the 384 stroke patients who were hospitalised at Dr. Cipto Mangunkusumo General Hospital Jakarta in 2014, the percentage of patients with ischemic stroke was $71.4 \%$. The large number of ischemic stroke patients treated at the hospital, the risks such patients face during treatment and the lack of a scoring system for predicting the likelihood of pneumonia in stroke patients formed the basis for the authors' decision to screen pneumonia in ischemic stroke patients using the AIS-SAP measuring instrument.

During the two-week data collection process, 16 ischemic stroke patients were screened for the risk of pneumonia following ischemic stroke. Of those 16 patients, nine were male and seven were female. Palm et al. (2012) found a statistically significant relationship between the male sex and the incidence of ischemic stroke $(p=0.04)$. Their study also revealed that the incidence of ischemic stroke tends to be higher in men than in women. The American Heart Association (AHA) has stated that stroke is more common in men, which implicitly increases the chance of male patients developing PSP (Haast et al., 2012). Indeed, as PSP is associated with sex hormones, it is known to be more common in male patients (Liu et al., 2018). 
The mean age of the 16 patients was 55.69 years (range: $23-76$ years). Age is recognised as one of the critical risk factors for stroke. Every ten years of age after the age of 55 years, the average risk of stroke more than doubles in both men and women. Sex is also an important factor because many studies have reported that the risk of death from stroke is higher in males aged less than 85 years, while in females, it is higher in those aged over 85 years (Lori, 2011).

PSP is more common following ischemic stroke than haemorrhagic stroke. A number of characteristics, including stroke onset $<48$ hours, are associated with a higher severity of stroke, and during this period, the risk of PSP increases. Moreover, a lesion located in the left hemisphere is associated with a higher NIHSS value, which indicates a more severe stroke. The onset of pneumonia after 48 hours indicates an increase in the length of a patient's stay in hospital, meaning that the risk of suffering from hospital-acquired infections (HAIs) also increases (Hassan et al., 2010; Wu et al., 2015).

Characteristics of stroke onset hypertension are known to be the most common stroke risk factor (Muela et al., 2017; O'Donnell et al., 2010). Other characteristics that indicate the risk of PSP occur in patients with decreased level of consciousness, dysphagia, and hemiparesis. Decreased level of consciousness affects the incidence of PSP because it will decrease the protective cough reflex, interfere with the function of the lower esophageal sphincter and interfere with the coordination between breathing and swallowing so that it has the same effect as dysphagia, namely increasing the risk of aspiration (Hannawi et al., 2013).

The higher the disability of stroke patients, the higher the tendency for aspiration to occur. Patients with hemiparesis tend to be immobilized so they have more sputum accumulation and increase the chance of infection (Wang et al., 2013). Based on previous research, early mobilization without possible contraindications can reduce the risk of PSP. Early mobilization is known to reduce the risk of aspiration and increase the clearance of airway secretions (Hannawi et al., 2013; Pássaro et al., 2016).

Damage to the brain of stroke patients results in an immunocompromised process so that the patient become susceptible to infection. In addition, this brain damage also makes the protection of the airway decrease, and swallowing problem occur. These all enhance the process of aspiration. The higher degree of stroke severity indicates that the brain damage is also serious. Therefore, the higher the stroke severity, the higher the risk of aspiration that results in an increase of PSP incidence (Almeida et al., 2015).

Gong et al. (2016) conducted a risk score validation study to predict PSP in patients with ischemic stroke. Gong used data from West China Hospital and obtained a sensitivity of $69.83 \%$ and a specificity of scoring $\mathrm{A}^{2} \mathrm{DS}^{2} 65.56 \%$. While the AIS - APS scoring obtained a sensitivity of $76.45 \%$ and a specificity of $62.56 \%$. According to Gong's research, the value of both diagnostic tools is quite good, with the AIS-APS slightly superior compared to $\mathrm{A}^{2} \mathrm{DS}^{2}$ and the value of ROC 0.758 versus 0.728 . Gong concluded that the tool with the best diagnostic capability is AIS-APS compared to $\mathrm{A}^{2} \mathrm{DS}^{2}$.

Hoffmann et al. (2012) conducted a study to develop a clinical score predictor of pneumonia in stroke patients. Hoffman used two data for his research, for the derivation study Hoffman used the Berlin Stroke Register (BSR) and for the validation study he used the stroke archive from North-West Germany (NSWR). Hoffman got the ROC value of the derivation study 0.837 while the validation study was 0.835 ; this result is higher than the result obtained by the researcher, which is 0.754 . From these results, Hoffman stated that $\mathrm{A}^{2} \mathrm{DS}^{2}$ could be a good measuring tool to predict post-stroke pneumonia. In the derivation study, Hoffman scored a sensitivity of $72.0 \%$ and a specificity of $67.0 \%$. This result is consistent with the results obtained by the researchers, in which $\mathrm{A}^{2} \mathrm{DS}^{2}$ has a sensitivity that is quite good so that it can be used as a filter for pneumonia in stroke patients.

In order to validate the AIS-APS clinical score they created, Ji et al. (2013) carried out internal validation and derivation studies using the China National Stroke Registry (CNSR), which is the most significant stroke archive in the People's Republic of China (PRC). This archive is the national archive, multicentre, and include prospective patients with consecutive acute cerebrovascular events. For external validation of the AIS-APS score, Ji used the Chinese Intracranial Atherosclerosis Study (CICAS), a prospective multicentre study investigating the prevalence, risk factors, and consequences of intracranial atherosclerosis in patients with ischemic stroke.

In the internal validation study, Ji obtained AIS-APS sensitivity of $72.5 \%$, specificity of $66.7 \%$ and ROC of 0.759. In the derivation study, Ji et al. got the AIS - APS sensitivity results of $79.3 \%$ for sensitivity, $76.9 \%$ specificity, and the ROC value was 0.797 . In the external validation study, Ji, using 
CICAS, got AIS-APS sensitivity, $72.8 \%$ sensitivity, $80.2 \%$ specificity and 0.792 ROC value. Statistically, AIS-APS is better, but for clinical use, it is more recommended to use $\mathrm{A}^{2} \mathrm{DS}^{2}$ for several reasons: 1) $\mathrm{A}^{2} \mathrm{DS}^{2}$ has the same sensitivity as AIS - APS, so it has the same ability to perform screening for pneumonia in acute ischemic stroke. 2) $\mathrm{A}^{2} \mathrm{DS}^{2}$ has fewer assessment items than AIS-APS, making it easier and faster to assess the possibility of pneumonia in acute stroke. 3) $\mathrm{A}^{2} \mathrm{DS}^{2}$ and AIS - APS have diagnostic values in the same range, 0.793 on AIS-APS compared to $0.70,754$ on A2DS2. Statistically, both values are in the intermediate category. The continuation of the implementation of competency-based clinical practice is implementing the Ventilator Associated Pneumonia bundle of care, Hospital Acquired Pneumonia bundle of care and Hospital-Acquired Infections Hospital Infection organized by the Prevention and Infection Control Committee.

\section{CONCLUSION}

The application of evidence-based nursing practice to 16 ischemic stroke patients showed that $\mathrm{A}^{2} \mathrm{DS}^{2}$ screening was effective in predicting the risk of pneumonia in acute ischemic stroke.

\section{REFERENCE}

Almeida, S. R., Bahia, M. M., Lima, F. O., Paschoal, I. A., Cardoso, T. A., \& Li, L. M. (2015). Predictors of pneumonia in acute stroke in patients in an emergency unit. Arq Neuropsiquiatr, 73(5), 415-419. https://doi.org/10.1590/0004-282x20150046

Anindhita, T., \& Wiratman, W. (2017). Buku ajar neurologi. Departemen Neurologi FKUI-RSCM.

Gong, S., Zhou, Z., Zhou, M., Lei, Z., Guo, J., Chen, N., \& He, L. (2016). Validation of risk scoring models for predicting stroke-associated pneumonia in patients with ischaemic stroke. Stroke Vasc Neurol, 1(3), 122-126. https://doi.org/10.1136/svn-2016-000025

Haast, R. A., Gustafson, D. R., \& Kiliaan, A. J. (2012). Sex differences in stroke. J Cereb Blood Flow Metab, 32(12), 2100-2107. https://doi.org/10.1038/jcbfm.2012.141

Hannawi, Y., Hannawi, B., Rao, C. P., Suarez, J. I., \& Bershad, E. M. (2013). Stroke-associated pneumonia: major advances and obstacles. Cerebrovasc Dis, 35(5), 430-443. https://doi.org/10.1159/000350199

Hassan, M., Tuckman Howard, P., Patrick Robert, H., Kountz David, S., \& Kohn Jennifer, L. (2010). Hospital length of stay and probability of acquiring infection. International Journal of Pharmaceutical and Healthcare Marketing, 4(4), 324-338. https://doi.org/10.1108/17506121011095182

Hoffmann, S., Malzahn, U., Harms, H., Koennecke, H. C., Berger, K., Kalic, M., Walter, G., Meisel, A., \& Heuschmann, P. U. (2012). Development of a clinical score (A2DS2) to predict pneumonia in acute ischemic stroke. Stroke, 43(10), 2617-2623. https://doi.org/10.1161/strokeaha.112.653055

Ji, R., Shen, H., Pan, Y., Wang, P., Liu, G., Wang, Y., Li, H., \& Wang, Y. (2013). Novel risk score to predict pneumonia after acute ischemic stroke. Stroke, 44(5), 1303-1309. https://doi.org/10.1161/strokeaha.111.000598

Kemenkes-RI. (2013). Riset kesehatan dasar 2013. http://www.depkes.go.id

Kulnik, S. T., Birring, S. S., Moxham, J., Rafferty, G. F., \& Kalra, L. (2015). Does respiratory muscle training improve cough flow in acute stroke? Pilot randomized controlled trial. Stroke, 46(2), 447-453. https://doi.org/10.1161/strokeaha.114.007110

Kulnik, S. T., Rafferty, G. F., Birring, S. S., Moxham, J., \& Kalra, L. (2014). A pilot study of respiratory muscle training to improve cough effectiveness and reduce the incidence of pneumonia in acute stroke: study protocol for a randomized controlled trial. Trials, 15, 123. https://doi.org/10.1186/1745-6215-15$\underline{123}$

Li, L., Zhang, L.-H., Xu, W.-P., \& Hu, J.-M. (2014). Risk assessment of ischemic stroke associated pneumonia. World journal of emergency medicine, 5(3), 209-213. https://doi.org/10.5847/wjem.j.issn.1920-8642.2014.03.009

Li, Y., Song, B., Fang, H., Gao, Y., Zhao, L., \& Xu, Y. (2014). External validation of the A2DS2 score to predict stroke-associated pneumonia in a Chinese population: a prospective cohort study. PLoS One, 9(10), e109665. https://doi.org/10.1371/journal.pone.0109665

Liu, D. D., Chu, S. F., Chen, C., Yang, P. F., Chen, N. H., \& He, X. (2018). Research progress in strokeinduced immunodepression syndrome (SIDS) and stroke-associated pneumonia (SAP). Neurochem Int, 
114, 42-54. https://doi.org/10.1016/j.neuint.2018.01.002

Lori, A. (2011). Ischaemic Stroke. CME Resource.

Muela, H. C., Costa-Hong, V. A., Yassuda, M. S., Moraes, N. C., Memória, C. M., Machado, M. F., Macedo, T. A., Shu, E. B., Massaro, A. R., Nitrini, R., Mansur, A. J., \& Bortolotto, L. A. (2017). Hypertension Severity Is Associated With Impaired Cognitive Performance. J Am Heart Assoc, 6(1). https://doi.org/10.1161/jaha.116.004579

O'Donnell, M. J., Xavier, D., Liu, L., Zhang, H., Chin, S. L., Rao-Melacini, P., Rangarajan, S., Islam, S., Pais, P., McQueen, M. J., Mondo, C., Damasceno, A., Lopez-Jaramillo, P., Hankey, G. J., Dans, A. L., Yusoff, K., Truelsen, T., Diener, H. C., Sacco, R. L., . . Yusuf, S. (2010). Risk factors for ischaemic and intracerebral haemorrhagic stroke in 22 countries (the INTERSTROKE study): a case-control study. Lancet, 376(9735), 112-123. https://doi.org/10.1016/s0140-6736(10)60834-3

Palm, F., Urbanek, C., Wolf, J., Buggle, F., Kleemann, T., Hennerici, M. G., Inselmann, G., Hagar, M., Safer, A., Becher, H., \& Grau, A. J. (2012). Etiology, risk factors and sex differences in ischemic stroke in the Ludwigshafen Stroke Study, a population-based stroke registry. Cerebrovasc Dis, 33(1), 69-75. https://doi.org/10.1159/000333417

Pássaro, L., Harbarth, S., \& Landelle, C. (2016). Prevention of hospital-acquired pneumonia in nonventilated adult patients: a narrative review. Antimicrobial Resistance \& Infection Control, 5(1), 43. https://doi.org/10.1186/s13756-016-0150-3

Sutbeyaz, S. T., Koseoglu, F., Inan, L., \& Coskun, O. (2010). Respiratory muscle training improves cardiopulmonary function and exercise tolerance in subjects with subacute stroke: a randomized controlled trial. Clin Rehabil, 24(3), 240-250. https://doi.org/10.1177/0269215509358932

Wang, K. W., Chen, H. J., Lu, K., Liliang, P. C., Huang, C. K., Tang, P. L., Tsai, Y. D., Wang, H. K., \& Liang, C. L. (2013). Pneumonia in patients with severe head injury: incidence, risk factors, and outcomes. J Neurosurg, 118(2), 358-363. https://doi.org/10.3171/2012.10.Jns127

Wu, O., Cloonan, L., Mocking, S. J., Bouts, M. J., Copen, W. A., Cougo-Pinto, P. T., Fitzpatrick, K., Kanakis, A., Schaefer, P. W., Rosand, J., Furie, K. L., \& Rost, N. S. (2015). Role of Acute Lesion Topography in Initial Ischemic Stroke Severity and Long-Term Functional Outcomes. Stroke, 46(9), 2438-2444. https://doi.org/10.1161/strokeaha.115.009643 